\title{
Management of renocolic fistula following abdominal trauma from a Gunshot: Two cases reports
}

\author{
Hamdoune Abdelaziz, MD; Ilyas Adourrouj, MD; Yassine Elabiad, MD; Abdellatif Janane, MD; \\ Mohammed Ghadouane, MD; Ahmed Ameur, MD; Mohammed Abbar, MD
}

Department of Urology, Military Hospital Med V, Rabat, Morocco

Cite as: Can Urol Assoc J 2014;8(3-4):e207-9. http://dx.doi.org/10.5489/cuaj.1057 Published online March 11, 2014.

\section{Abstract}

The renocolic fistula is a rare entity. We report 2 cases of renocolic fistula penetrating an abdominal trauma from a gunshot.

\section{Introduction}

An enterorenal fistula is rare among renocolic fistulas. The first description of a renocolic fistula was reported by Hippocrates in 460 BC. Few are associated with abdominal trauma. ${ }^{1}$ We report 2 cases of a renocolic fistula as a complication of an abdominal wound due to a gunshot.

\section{Case 1}

Our first case is a 44-year-old male who suffered an abdominal wound, due to a gunshot. Upon examination, he was hemodynamically unstable. His blood pressure was $60 / 40 \mathrm{mmHg}$; he was tachycardic with discoloured conjunctives. He had 2 wounds: one at the right hypochondrium and the other at the right thigh. An ultrasound detected effusion peritoneal and retroperitoneal. An abdominopelvic computed tomography (CT) scan showed the presence of a ureteral lesion with extravasation of contrast material in the retroperitoneum and in the colon (Fig. 1).

After anesthetic control, the patient underwent a retrograde uretropyeloraphy showing a fistula ureterocolic on the right side (Fig. 2). After surgical exploration via laparotomy, we found a hemoperitoneum $(2.5 \mathrm{~L})$, which was quickly evacuated. His liver was extensively wounded (segment $\mathrm{V}$ and $\mathrm{VI}$ ) and was sutured (hemostasis laborious. Moreover, he had multiple wounds of the right colonic flexure which were repaired by resection anastomosis. We also found a retroperitoneal hematoma lateralized to the right, with a 7-mm wound on the inferior vena cava. Due to the extent of the fistula and propylite, we decided to do a nephrectomy. The outcome was favourable and the restoration of continuity digestion was performed after 45 days.

\section{Case 2}

Our second case is a 28-year-old male He suffered an accidental abdominal wound via an automatic gun. On admission, he was hemodynamically unstable and his wound was clean with an inlet at the left hypochondrium. We found an outlet on the left lumbar fossa.

The abdomen was distended and sensitive in its entirety and the left lumbar fossa had hematic urine. An ultrasound identified a retroperitoneal effusion. Surgical exploration via laparotomy revealed hemoperitoneum, which evacuated quickly, a wound to the splenic flexure, which was repaired by resection anastomosis.

Postoperatively, a uro-CT revealed a hematoma perirenal associated with renal fracture stage III according to Chatelain (Fig. 3). Twenty-one days later the patient presented with fever associated with left back pain, hematuria with clots with intravesical pneumaturia and diarrhea. We implemented double current irrigation to deplete the hematuria and then we started antibiotic treatment.

The presence of air bubbles in the calyces, renal pelvis and the bladder, and the passage of the contrast in intracolonic were signs of a renocolic fistula. The patient underwent a retrograde pyelo-ureterography and a double J catheter was inserted. Via a laparotomy, we found the renocolic fistula early. The postoperative day 4 , the patient had acute abdominal pain. A second surgery revealed a small bowel volvulus sphacelus with handle; it was resected with a double ileostomy.

The outcome was favourable. The J stent was removed during the fourth week and the the patient resumed normal digestion after 60 days. 


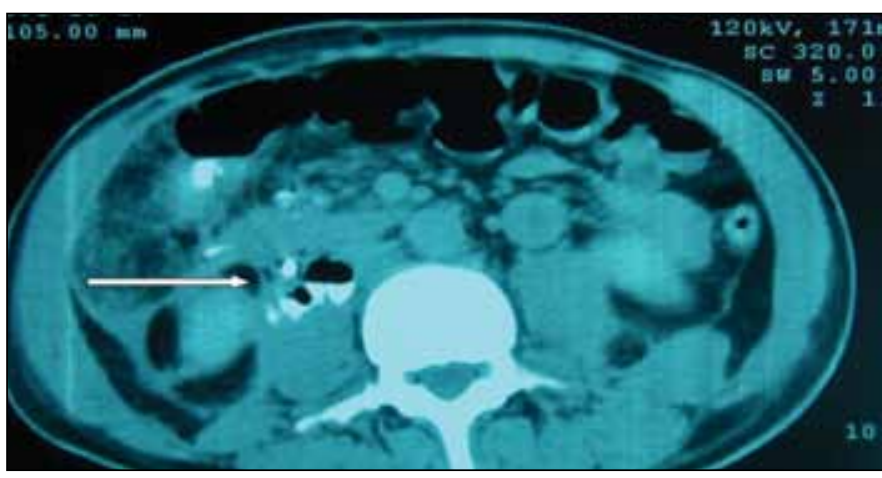

Fig. 1. A computed tomography scan showing a lesion ureteral extravasation in the retroperitoneal and the colon.

\section{Discussion}

Among reno-digestive fistulas, those involving the kidney and colon are the most common. Bissada and colleagues have compiled 59 renocolic fistulas among the 96 renodigestive fistulas. ${ }^{2}$ Before antibiotics, $80 \%$ of fistulas were pyo-nephrogenic in origin and a third were pyo-tuberculosis. Currently, the role of kidney infections in the development of fistulas has decreased. ${ }^{3}$

The etiology of fistulas can be either renal tuberculosis or calculous pyonephrosis. ${ }^{3}$ It is extremely rare that a renocolic fistula develops due to a colonic lesion.

Post-traumatic fistulas are often iatrogenic. ${ }^{3}$ In their series, Bissada and colleagues reported on 5 entero-renal post-traumatic fistulas secondary to gunshot wounds. Arthur and Morris reported on 4 cases of renocolic fistuls which occurred after abdominal trauma; these patients did not undergo surgical treatment. ${ }^{4}$

In 1993, Melvin and colleagues were the first to describe a renocolic fistula due to an abdominal trauma by firearm. ${ }^{1}$ In 2001 Herbert and colleagues reported on the second case. ${ }^{5}$ After searching based on Pubmed using keywords (i.e., renocolic, nephrocolic, fistula, trauma and gunshot), we found that our case is the third report.

Melvin and colleagues propose 2 explanations on the appearance of a renocolic fistula after a surgical wound repair due to abdominal trauma. ${ }^{1}$ Firstly, colon surgery can induce inflammation and the localized abscess can erode the perirenal hematoma. Secondly, perirenal fuser urine can flood the colonic anastomosis and create a fistula. ${ }^{1}$

Clinically, gastrointestinal symptoms often dominate the scene; nausea, vomiting and diarrhea are very common. Moreover, lower back pain and pneumaturia are rare. ${ }^{3}$ In the absence of pneumaturia, the diagnosis is done radiologically either by barium enema, retrograde pyelogram, CT scan or fistulogram. ${ }^{3}$ In our 2 cases, the pneumaturia was very evocative and the uro-CT was able to confirm the diagnosis.

Treatment usually consists of a nephrectomy associated with colonic resection-anastomosis; ${ }^{1,3}$ this can be achieved

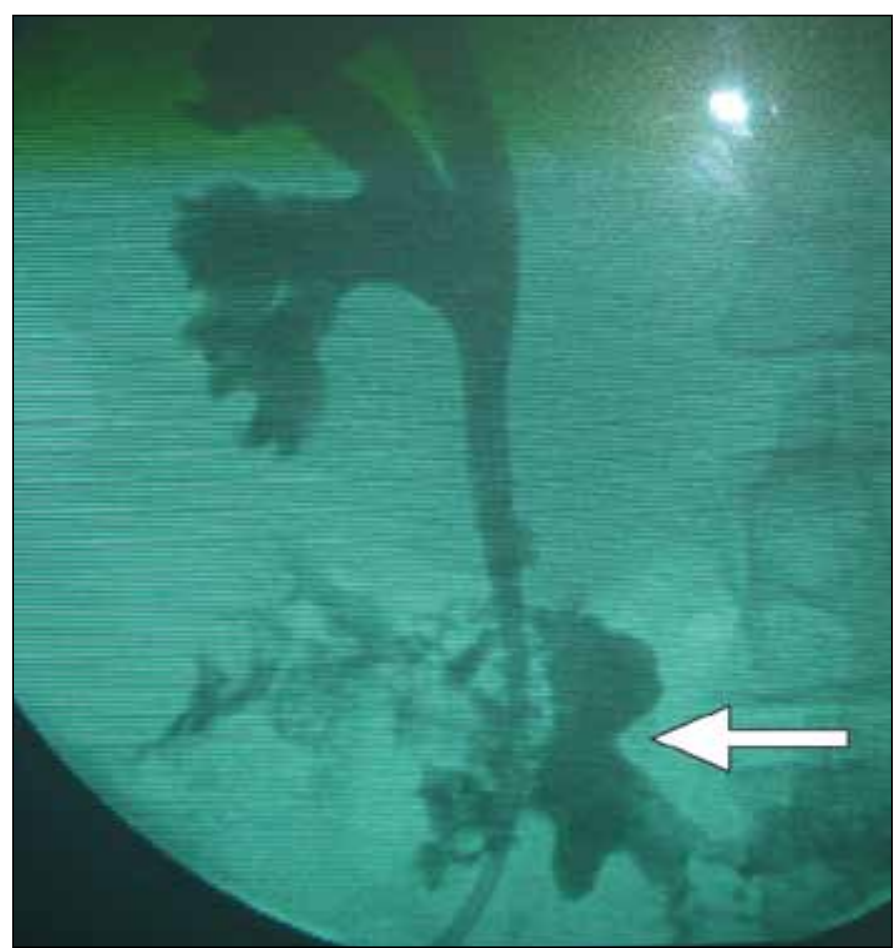

Fig. 2. A urographic picture showing extravasation of contrast at the ureteral.

by either open or laparoscopic surgery. ${ }^{6}$ However, in most cases, a conservative approach is appropriate.

The cases reported by Melvin and colleagues were wellresolved after kidney drainage collection and a transverse colostomy. In Herbert and colleagues' case report, the patient improved after percutaneous drainage and simple correction of the associated gastrointestinal lesions. ${ }^{5}$ Vanderbrink and colleagues recently described the case of a fistula secondary to renocolic cryoablation of renal cell carcinoma, which resolved after ureteral stent placement. ${ }^{7}$

Our therapeutic approach is valid because the kidney has been preserved, despite some postoperative problems in the

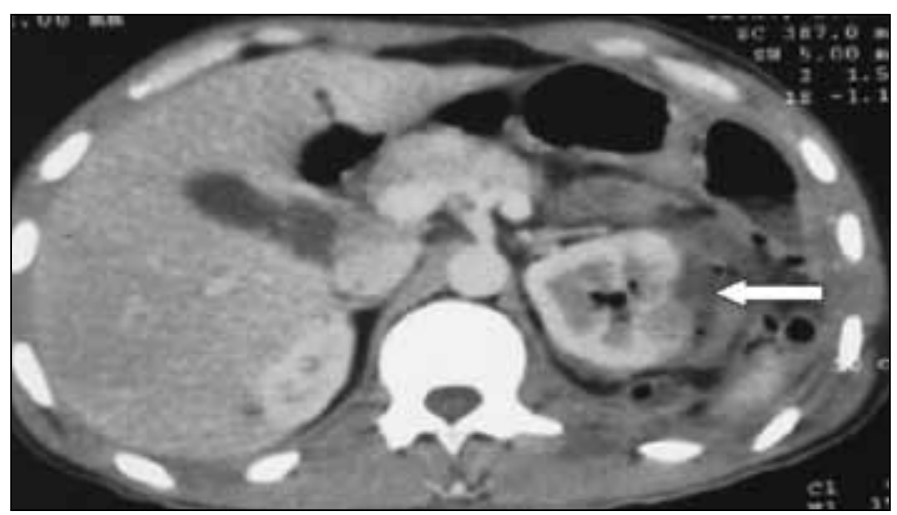

Fig. 3. A scannographic picture showing the presence of air in the pyelocalicielles cavities and a hematoma perirenal associated with renal fracture stage III according to Chatelain. 
second case. These data make nephrectomy required only if there is previous renal disease or if the kidney is damaged. ${ }^{1}$

\section{Conclusion}

Renocolics fistulas are rare. latrogenic causes currently dominate the scene. The prognosis depends on the etiology and coverage of the fistula. Treatment usually consists of a nephrectomy with colonic resection-anastomosis, but conservative treatment is the rule if the kidney is functional.

Competing interests: Dr. Abdelaziz, Dr. Adourrouj, Dr. Elabiad, Dr. Janane, Dr. Ghadouane, Dr. Ameur and Dr. Abbar all declare no competing financial or personal interests.

This paper has been peer-reviewed.

\section{References}

1. Melvin WS, Burak WE, Flowers IL, et al. Reno-colic fistula following primary repair of the colon: A case report. J Trauma 1993;35:956. http://dx.doi.org/10.1097/00005373-199312000-00026

2. Bissada NK, Cole AT, Fried FA. Reno-alimentary fistula: An unusual urological problem. J Urol 1973;110:273-6.

3. Touiti D, Ameur A, Zrara I, et al. Les fistules pyélocoliques à propos d'une observation. Ann Urol 2001;35:44-6. http://dx.doi.org/10.1016/S0003-4401 (01)80012-7

4. Arthur GW, Morris DG. Reno-alimentary fistulae. Br J Surg 1966;53:396. http://dx.doi.org/10.1002/bjs. 1800530503

5. Herbert FB, Goodacre B, Neal Jr DE. Successful conservative management of nephrocolic fistula. J Endourol 2001;15:281-3. http://dx.doi.org/10.1089/089277901750161773

6. Bachelier $M N$, Carteron $M$, Gazaigne J, et al. Fistule rénocolique compliquant une pyélonéphrite xanthogranulomateuse (un cas traité par laparoscopie). Prog Urol 2004;14:67-9.

7. Vanderbrink BA, Rastinehad A, Caplin D, et al. Successful conservative management of colorenal fistula after percutaneous cryoablation of renal-cell carcinoma. J Endourol 2007;21:726-9. http://dx.doi.org/10.1089/end.2006.0211

Correspondence: Dr. Hamdoune Abdelaziz, Department of Urology, Military Hospital Med V, Rabat, Morocco; aziuro@gmail.com 